\title{
Simulations of BWRO systems under different feedwater characteristics. Analysis of operation windows and optimal operating points
}

\author{
A. Ruiz-García ${ }^{a, *}$, I. Nuez ${ }^{b}$, M.D. Carrascosa-Chisvert ${ }^{c}$, J.J. Santana ${ }^{c}$ \\ ${ }^{a}$ Department of Mechanical Engineering, University of Las Palmas de Gran Canaria, Campus Universitario de Tafira, E-35017 Las Palmas de Gran Canaria, Gran Canaria, \\ Spain \\ ${ }^{\mathrm{b}}$ Department of Electronic and Automatic Engineering, University of Las Palmas de Gran Canaria, Campus Universitario de Tafira, E-35017 Las Palmas de Gran Canaria, \\ Gran Canaria, Spain \\ ${ }^{\mathrm{c}}$ Department of Process Engineering, University of Las Palmas de Gran Canaria, Campus Universitario de Tafira, E-35017 Las Palmas de Gran Canaria, Gran Canaria, \\ Spain
}

\section{A R T I C L E I N F O}

\section{Keywords:}

Desalination

Brackish water

Optimal operation

Reverse osmosis

Operation window

\begin{abstract}
A B S T R A C T
Reverse osmosis (RO) is the leading technology for desalinating seawater and brackish water (BW). In general, the desalination efficiency of BW is higher than that of seawater due to its lower total dissolved solids content. In addition to membrane fouling, fluctuations in the feedwater source are one of the main problems that affect desalination systems. These variations can have a significant impact on the operating parameters and efficiency of BWRO systems. In this work, hydrochemical fluctuations in well groundwater were used to evaluate the different operation windows of two BWRO system configurations, as well as their optimal operating points in terms of minimum specific energy consumption $(S E C)$ and maximum flow recovery $(R)$. Both configurations comprised two stages and 6 BWRO spiral wound membrane elements per pressure vessel (PV). One configuration had 2 and 1 PVs in the first and second stages respectively, and the other 3 and 2 PVs. Both systems were simulated using a range of feed flow and feed pressure values in addition to the inorganic compositions of 24 feedwater samples taken over a 10-year period. The results showed wider operation windows for the 3:2 than the 2:1 configuration. A common operation window (able to operate with all 24 feedwater samples) with wide operating margins was obtained for each configuration. For the 2:1 configuration, the 24-sample average SEC, average maximum SEC and average minimum SEC of this common operation window were 0.760, 1.198 and $0.339 \mathrm{kWh} \mathrm{m}^{-3}$, respectively, while the corresponding $R$ values were $33.47,67.66$ and $19.86 \%$.
\end{abstract}

\section{Introduction}

Reverse osmosis (RO) desalination has become a commonly adopted solution to deal with water scarcity problems [1]. Generally, RO processes are used to separate solutes from either seawater or brackish water (BW) in order to obtain clean water suitable for, among other uses, human consumption and irrigation [1,2]. These processes can be classified into two groups depending on the salinity of the feedwater. Desalination plants which employ RO to treat brackish water (BWRO) handle feedwaters with a total dissolved solids $\left(T D S_{\mathrm{f}}\right)$ content that ranges from $500 \mathrm{mg} \mathrm{L}^{-1}$ to $10,000 \mathrm{mg} \mathrm{L}^{-1}$, whereas the $T D S_{\mathrm{f}}$ content of the feedwaters of seawater RO desalination plants (SWRO) tends to be around $30,000 \mathrm{mg} \mathrm{L}^{-1}$. The efficiency of the RO process depends on several factors, including feedwater composition, RO membrane characteristics, RO system design (stages, passes, etc.), and the operational parameters. Significant efforts have been made in the last two decades to improve the efficiency of RO processes. Work has been carried out, for example, on improving the pretreatment stage to reduce the fouling impact on RO membranes [3,4], on the use of RO membranes for brine desalination [5], and on design of new RO membranes [6,7], etc. While the use of energy recovery devices (ERDs) in SWRO systems is key to reducing specific energy consumption (SEC) [8], these devices are not commonly used in BWRO systems given their lower operating pressures and brine flow rates [9]. Nonetheless, even without ERDs, BWRO is generally more efficient than SWRO due to the lower $T D S_{\mathrm{f}}$ content.

As well as the characteristics of the BWRO membranes [10-12], it is extremely important to take into consideration the characteristics of the feedwater in the design and operation of BWRO plants. As high flow recoveries $(R)$ are achievable, the solubility of sparingly soluble mineral salts (e.g. silica $\left(\mathrm{SiO}_{2}\right)$, calcium carbonate $\left(\mathrm{CaCO}_{3}\right)$, calcium sulphate dihydrate (denoted simply as $\left.\mathrm{CaSO}_{4}\right)$, barium sulphate $\left(\mathrm{BaSO}_{4}\right)$, strontium sulphate $\left(\mathrm{SrSO}_{4}\right)$ and calcium fluoride $\left(\mathrm{CaF}_{2}\right)$ ) could be exceeded.

\footnotetext{
* Corresponding author.

E-mail addresses: alejandro.ruiz@ulpgc.es (A. Ruiz-García), ignacio.nuez@ulpgc.es (I. Nuez), juan.santana@ulpgc.es (J.J. Santana).
} 


$\begin{array}{ll}\text { Nomenclature } \\ \text { Acronyms } \\ \text { BWRO } & \text { Brackish water reverse osmosis } \\ \text { ERD } & \text { energy recovery device } \\ \text { PV } & \text { pressure vessel } \\ \text { RO } & \text { reverse osmosis } \\ \text { SWRO } & \text { seawater reverse osmosis } \\ \text { A } & \text { average water permeability coefficient }\left(\mathrm{m} \mathrm{d}^{-1} \mathrm{~kg}^{-1} \mathrm{~cm}^{2}\right) \\ B & \text { average ion permeability coefficient }\left(\mathrm{m} \mathrm{d}^{-1}\right) \\ C & \left.\text { concentration (mg } \mathrm{L}^{-1}\right) \\ F F & \text { flow factor } \\ J & \text { flux per unit area }\left(\mathrm{m}^{3} \mathrm{~m}^{-2} \mathrm{~s}^{-1} \text { or } \mathrm{kg} \mathrm{m}^{-2} \mathrm{~s}^{-1}\right) \\ K_{\text {sp }} & \text { solubility product } \\ m & \text { molal concentration }\left(\mathrm{mol} \mathrm{kg}^{-1}\right) \\ N D P & \text { net driven pressure }\left(\mathrm{kg} \mathrm{cm}^{-2}\right) \\ p & \text { pressure }(\mathrm{kg} \text { cm }\end{array}$

\section{$T$}

TCF

TDS

$Y$

\section{Greek letters}

$\alpha \quad$ water price $\left(€ \mathrm{~m}^{-3}\right)$

$\beta \quad$ energy consumption price $\left(€ \mathrm{kWh}^{-1}\right)$

$\Delta \pi \quad$ osmotic pressure gradient $\left(\mathrm{kg} \mathrm{cm}^{-2}\right)$

$\Delta p \quad$ pressure drop $\left(\mathrm{kg} \mathrm{cm}^{-2}\right)$

$\pi \quad$ osmotic pressure $\left(\mathrm{kg} \mathrm{cm}^{-2}\right)$

Subscripts

b brine

f feed

i membrane element $i$

$\mathrm{j} \quad$ ion $\mathrm{j}$

$\max$ maximum

min minimum

m membrane

$\mathrm{p}$ permeate

s solute
This can cause scaling, one of the biggest membrane fouling problems in BWRO desalination $[13,14]$. To counter this problem, antiscalant has to be used in the pretreatment or intermediate demineralization treatments [15] to increase $R$ [16]. Usually, $T D S_{\mathrm{f}}$ and temperature (T) variations are more common in brackish water than seawater feedwater sources [17]. Such variations, when they occur, complicate the efficient operation of BWRO systems [18-20]. Yan-Yue Lu et al. [21] studied the optimum design of RO systems under different $T D S_{\mathrm{f}}$ and product specifications. They focused on optimizing an equation related to the capital and operating costs, and considered the incorporation of ERDs and interstage pumps in the BWRO system design. Different $T D S_{\mathrm{f}}$ values (16, 12, 6 and $3 \mathrm{~g} \mathrm{~L}^{-1} \mathrm{NaCl}$ ) were used. Their analysis involved use of the Filmtec ${ }^{\mathrm{TM}} \mathrm{BW} 30-400$ membrane. They obtained different BWRO configurations (stages, interstage pumps, number of pressure vessels (PVs), BWRO elements per PV) for each $T D S_{\mathrm{f}}$, and all the BWRO systems had an ERD. K. M. Sassi and I. M. Mujtaba [22] studied the optimal design and operation of a BWRO system considering membrane fouling. A simulation was carried out to validate the code with experimental data from another published work [23], and a sensitivity analysis was also performed. They also used the Filmtec ${ }^{\mathrm{TM}}$ BW30-400 membrane. The BWRO system had two stages, each with two PVs of three membrane elements. The sensitivity analysis that they performed considered a feed pressure $\left(p_{\mathrm{f}}\right)$ from 0.6 to $2.5 \mathrm{MPa}$, increasing the number of membrane elements per PV (up to 7), $T D S_{\mathrm{f}}\left(2.5\right.$ and $\left.5 \mathrm{~g} \mathrm{~L}^{-1}\right)$ and feed spacers. The feed flow $\left(Q_{\mathrm{f}}\right)$ was considered constant $\left(20.4 \mathrm{~m}^{3} \mathrm{~h}^{-1}\right)$, and the fouling effect was evaluated through a previously proposed model for water permeability coefficient decline [24]. Their analysis was done without limiting $R$ due to scaling or varying the $Q_{\mathrm{f}}$. M. Li and B. Noh [25] studied the validation of a model-based optimization of BWRO operation. They carried out their study on the basis of constant $Q_{\mathrm{f}}\left(350 \mathrm{~m}^{3}\right.$ $\left.\mathrm{h}^{-1}\right)$ and $T D S_{\mathrm{f}}\left(0.95 \mathrm{~g} \mathrm{~L}^{-1}\right)$. As the BWRO plant was already built, the study focused on its optimization. The same plant was used by M. Li [26] in a later work to optimize the SEC, as well as in another study related to the use of multitrains that allow different operating conditions [27]. Y. Du et al. [28] analyzed the optimization of an RO systems network involving both SWRO and BWRO. The analysis included use of the Filmtec ${ }^{\mathrm{TM}} \mathrm{BW} 30-400$ membrane, as well as ERD and interstage pumps. Constant $T\left(20{ }^{\circ} \mathrm{C}\right)$ and permeate flow $\left(120 \mathrm{~m}^{3} \mathrm{~h}^{-1}\right)$, and $T D S_{\mathrm{f}}$ rates of $16,12,6$ and $3 \mathrm{~g} \mathrm{~L}^{-1}$ were also considered. The objective function was formulated as a mixed integer nonlinear programming for minimizing the total cost or energy consumption subject to thermodynamic, technical and flexibility constraints. They established that RO systems with 2 stages were the best choice when $T D S_{\mathrm{f}}$ content was below $28 \mathrm{~g} \mathrm{~L}^{-1}$. The calculated BWRO systems for $T D S_{\mathrm{f}}$ from 3 to $16 \mathrm{~g}$ $\mathrm{L}^{-1}$ had ERDs and interstage pumps with different arrangements for each $T D S_{\mathrm{f}}$. A sensitivity analysis was also carried out, but only for a SWRO case. Mingheng Li conducted a further work on the optimization of SEC in RO systems [29]. This time, a unified mathematical model to describe both BWRO and SWRO desalination was developed. SEC was optimized considering different RO configurations, $R$, ERDs and interstage pumps. M.A. Al-Obaidi et al. [30] carried out a performance analysis of a full-scale BWRO plant with two passes. The impact of variations in $T D S_{\mathrm{f}}\left(1.098-1.318 \mathrm{~g} \mathrm{~L}^{-1}\right), Q_{\mathrm{f}}\left(74-88.8 \mathrm{~m}^{3} \mathrm{~h}^{-1}\right), p_{\mathrm{f}}$ (1-1.5 MPa) and $T\left(25-30{ }^{\circ} \mathrm{C}\right)$ on permeate concentration and $R$ was evaluated. The impact was assessed separately in that when one parameter was varied the rest were considered constant in the existing BWRO system. In a later work, and using the same full-scale BWRO plant, A. A. Alsarayreh et al. [31] undertook a simulation-based performance evaluation which considered different recycled ratios of brine. They concluded that it was possible to increase product capacity by around $3 \%$ with $100 \%$ recycle percentage of the high salinity brine stream. The same research group continued their work with the same plant, evaluating and minimizing the energy consumption [32]. They found it was possible to reduce total energy consumption by between $47 \%$ and $53.8 \%$ when compared with the calculations for the original design without an ERD. Y. D. Ahdab et al. [33] carried out a comprehensive investigation of brackish groundwater composition (in the United States) in relation to minimum desalination energy costs. They consider the desalination unit as a black box with inputs and outputs. They based the study on calculation of least work of separation which represents a baseline for SEC of desalination systems.

Most of the aforementioned works consider BWRO systems with ERDs, which is not usual. The use of interstage pumps is also uncertain given the low efficiency of these pumps and the added complexity in terms of operation and maintenance due to variations in the operating parameters. Most of these BWRO system configurations were designed 
considering constant $T D S_{\mathrm{f}}$ and/or $Q_{\mathrm{f}}$, but variation of these parameters can result in the BWRO system being unable to operate within the limits recommended by the membrane manufacturer or far from the optimal operating point. This paper aims to evaluate different operation windows (ranges of $Q_{\mathrm{f}}$ and $p_{\mathrm{f}}$ ) of 2-stage BWRO systems under variable $T D S_{\mathrm{f}}$ and $T$. For this purpose, a total of 24 well groundwater samples taken over the course of a 10 year period were analyzed and used, and a computational tool for the design and simulation of BWRO systems was employed which has been previously published and validated by the authors [34].

\section{Material and methods}

\subsection{Feedwater}

The groundwater well is located in the south of Gran Canaria (Canary Islands, Spain). Its coordinates are latitude $27^{\circ} 50^{\prime} 52.04^{\prime \prime} \mathrm{N}$, longitude $15^{\circ} 29^{\prime} 00.20^{\prime \prime} \mathrm{W}$, and an elevation of $160 \mathrm{~m}$ above mean sea level. The hydrochemistry of this well has previously been described by the authors, as well as how the samples were taken and processed for the determination of the different parameters [17]. The samples were taken over the course of a 10 year period, two or three analyses per year. Table 1 shows the $\mathrm{pH}, T$ and inorganic composition of the groundwater. The TDS considered were the sum of the analyzed ions. The highest TDS were found in sample $11\left(5815.20 \mathrm{mg} \mathrm{L}^{-1}\right)$ and the lowest in sample 20 (1218.79 $\mathrm{mg} \mathrm{L}^{-1}$ ). The silt density index (SDI) was assumed to be between 2 and 3, as is usual for this type of water after a microfiltration stage [35].

\subsection{BWRO systems considered}

The number of possible BWRO configurations to desalinate particular types of brackish water depends on the desired operating range (SEC, $R$, permeate concentration). Usually, an RO system with two stages is appropriate for BW desalination, as has been demonstrated in previous works $[28,34]$. Even if we consider only two stages, the number of possible configurations is still high. Another factor to be considered is the potential use of ERDs. Normally, the $R$ ratios are between 60 and $85 \%$ and the $Q_{\mathrm{f}}$ is limited by the source. In Gran Canaria island, the average $Q_{\mathrm{f}}$ of BWRO desalination plants is between 29 and
$34 \mathrm{~m}^{3} \mathrm{~h}^{-1}$ [36]. With these flow rates and the aforementioned $R$, the use of ERDs would be unusual. The installation of interstage pumps implies one more element to be considered in terms of operation and maintenance. While their deployment may be interesting from a theoretical point of view, from a practical perspective their use would be complex under variable operating conditions and consideration also needs to be given to the generally low efficiency of these pumps. Even without incorporating ERDs and interstage pumps, the number of possible solutions remains high in terms of the number of PVs per stage and the number of BWRO membrane elements per PV. With respect to the aforementioned $Q_{f}$, it seemed coherent to consider 3:2 (3 PVs in the first stage and 2 in the second stage) and 2:1 configurations. The number of simulations needed to evaluate the operation windows (range of possible $p_{\mathrm{f}}$ and $Q_{\mathrm{f}}$ ) for the 24 samples (Table 1) would be numerous. Installing too many BWRO membrane elements in series could cause operation and maintenance problems as the membranes get fouled, and the pressure drop limit recommended by the membrane manufacturer $(0.345 \mathrm{MPa})$ in a stage could be exceeded. The last simplification was to consider 6 BWRO membrane elements per PV in both stages, i.e. 3(6):2(6) and 2(6):1(6). As the algorithm used was previously validated with four full-scale BWRO desalination plants with the Filmtec ${ }^{\mathrm{TM}} \mathrm{BW} 30-400$ membrane element [34], this was the element selected for the simulations.

\subsection{Calculation algorithm}

\subsubsection{Estimation of maximum $R$}

One of the main limiting factors when designing BWRO desalination plants is the maximum $R$ ( $\left.R_{\max }\right)$ for scale prevention. This value depends on the feedwater characteristics and the antiscalant used in the pretreatment. The antiscalants considered and their theoretical power of inhibition of measured salts in the samples are shown in Table 2. The $R_{\max }$ for each antiscalant was calculated according to a previously published algorithm [16]. The highest value was selected as a constraint in the simulation algorithm. It should be noted that the calculated values are theoretical. In practice, it is not usual to reach the limit but to leave a safety margin.

\subsubsection{Process modeling}

The solution-diffusion [1,37] transport model was implemented in

Table 1

Feed water inorganic composition in $\mathrm{mg} \mathrm{L}^{-1}$.

\begin{tabular}{|c|c|c|c|c|c|c|c|c|c|c|c|c|c|}
\hline Sample & $\mathrm{pH}$ & $\mathrm{HCO}_{3}{ }^{-}$ & $\mathrm{Cl}^{-}$ & $\mathrm{SO}_{4}=$ & $\mathrm{NO}_{3}{ }^{-}$ & $\mathrm{Na}^{+}$ & $\mathrm{K}^{+}$ & $\mathrm{Ca}^{2+}$ & $\mathrm{Mg}^{2+}$ & $\mathrm{Fe}^{2+}$ & $\mathrm{SiO}_{2}$ & $T D S$ & $T$ \\
\hline 1 & 7.05 & 175 & 2620 & 165 & 7.9 & 400 & 29 & 474 & 475 & 0.6 & 60.5 & 4407.00 & 25.20 \\
\hline 2 & 6.94 & 155 & 2500 & 180 & 5.3 & 422 & 38 & 532 & 383 & 0.2 & 36 & 4251.50 & 25.60 \\
\hline 3 & 7.37 & 175 & 2650 & 168 & 5.3 & 450 & 30 & 561 & 406 & 0.15 & 55.7 & 4501.15 & 25.00 \\
\hline 4 & 7.48 & 100 & 2420 & 192 & 5.7 & 307 & 30 & 512 & 409 & 0.11 & 53.4 & 4029.21 & 25.10 \\
\hline 5 & 7.24 & 122 & 1715 & 150 & 6.9 & 257 & 28 & 368 & 292 & 0.09 & 52.5 & 2991.49 & 24.90 \\
\hline 6 & 7.27 & 216 & 2230 & 323 & 9.6 & 369 & 30 & 480 & 399 & 0.1 & 65 & 4121.70 & 25.50 \\
\hline 7 & 7.05 & 190 & 3180 & 306 & 3 & 458 & 17 & 783 & 483 & 0.35 & 57 & 5477.35 & 25.30 \\
\hline 8 & 7.05 & 167 & 2418 & 175 & 6 & 451 & 29 & 660 & 264 & 0.5 & 57 & 4227.50 & 25.00 \\
\hline 9 & 7.03 & 92 & 2680 & 166 & 4.3 & 339 & 35 & 605 & 428 & 0.13 & 30 & 4379.43 & 24.80 \\
\hline 10 & 7.46 & 287 & 2684 & 196 & 1 & 720 & 48 & 432 & 370 & 0.09 & 59 & 4797.09 & 25.40 \\
\hline 11 & 7.10 & 304 & 3362 & 180 & 2.2 & 830 & 85 & 566 & 453 & 1 & 32 & 5815.20 & 25.70 \\
\hline 12 & 7.10 & 305 & 3360 & 180 & 2 & 828 & 83 & 570 & 450 & 0.8 & 30 & 5808.80 & 25.00 \\
\hline 13 & 7.40 & 184 & 2420 & 182 & 1.4 & 324 & 32 & 570 & 390 & 0.27 & 56.3 & 4159.97 & 25.20 \\
\hline 14 & 7.10 & 185 & 2872 & 200 & 5 & 383 & 28.9 & 594 & 505 & 0.48 & 55.8 & 4829.18 & 25.10 \\
\hline 15 & 7.80 & 155 & 2610 & 209 & 0.5 & 399 & 38.1 & 645 & 405 & 0.21 & 92.9 & 4554.71 & 25.00 \\
\hline 16 & 7.40 & 152 & 2966 & 273 & 12.9 & 469 & 33.6 & 600 & 504 & 0.19 & 54.5 & 5065.19 & 24.80 \\
\hline 17 & 6.90 & 260 & 3023 & 218 & 5 & 425 & 36.9 & 632 & 552 & 0.08 & 54.7 & 5206.68 & 24.60 \\
\hline 18 & 7.70 & 173 & 2930 & 253 & 6.8 & 410 & 17 & 620 & 504 & 0.14 & 46 & 4959.94 & 25.70 \\
\hline 19 & 7.00 & 170 & 2758 & 232 & 7.2 & 363 & 38.2 & 669 & 546 & 0.15 & 50.8 & 4834.35 & 25.50 \\
\hline 20 & 7.60 & 215 & 484 & 85.6 & 13.6 & 208 & 11.7 & 76.8 & 78.1 & 0.094 & 45.9 & 1218.79 & 25.00 \\
\hline 21 & 8.04 & 193 & 1831 & 150 & 8.36 & 468 & 22.5 & 395 & 323 & 0.17 & 52.1 & 3443.13 & 25.50 \\
\hline 22 & 8.19 & 197 & 1715 & 148 & 8.1 & 622 & 28.6 & 423 & 308 & 0.11 & 34.2 & 3484.01 & 25.20 \\
\hline 23 & 7.72 & 227 & 654 & 108 & 6.73 & 214 & 15.6 & 120 & 88.5 & 1.21 & 66.6 & 1501.64 & 25.10 \\
\hline 24 & 7.58 & 196 & 2259 & 152 & 74.8 & 354 & 35.1 & 465 & 418 & 1.22 & 62.3 & 4017.42 & 25.00 \\
\hline
\end{tabular}


Table 2

Theoretical power of inhibition.

\begin{tabular}{|c|c|c|c|c|}
\hline \multirow[t]{2}{*}{ Salt } & \multicolumn{4}{|l|}{ Antiscalant } \\
\hline & Genesys LF & Genesys SI & Vitec 3000 & Vitec 4000 \\
\hline $\mathrm{CaCO}_{3}$ & $L S I \leq 2.6$ & $L S I \leq 2.4$ & $L S I \leq 3$ & $L S I \leq 2.5$ \\
\hline $\mathrm{CaSO}_{4}$ & $3.5 \cdot K_{\mathrm{sp}}$ & $3.5 \cdot K_{\mathrm{sp}}$ & $3.5 \cdot K_{\mathrm{sp}}$ & $3.5 \cdot K_{\mathrm{sp}}$ \\
\hline $\mathrm{SiO}_{2}$ & $210 \mathrm{mg} \mathrm{L}^{-1}$ & $375 \mathrm{mg} \mathrm{L}^{-1}$ & $120 \mathrm{mg} \mathrm{L}^{-1}$ & $2 \cdot$ saturation \\
\hline
\end{tabular}

the algorithm [34] as it usually provides results close to the real behavior of these systems. The transport equations used mean membrane element values, and the pressure drop in the permeate as well as $T$ changes along the RO systems were disregarded. The calculation algorithm considers some simplifications that are detailed in a previous work [34]. It additionally allows the use of various equations for determination of the polarization factor $\left(P F_{\mathrm{i}}\right)$ and the pressure drop along the BWRO membrane elements in the feed-brine side $\left(\Delta p_{\mathrm{fb}}\right)$. The following equations were used:

$Q_{\mathrm{p}}=A \cdot(\Delta p-\Delta \pi) \cdot S_{\mathrm{m}}$

where $Q_{\mathrm{p}}$ is the permeate flow, $A$ is the water permeability coefficient of the membrane, $(\Delta p-\Delta \pi)$ is the net driven pressure (NDP) and $S_{\mathrm{m}}$ is the membrane area.

Solute transport equation:

$Q_{\mathrm{s}}=B \cdot \Delta C \cdot S_{\mathrm{m}}$

where $Q_{S}$ is the solute flow through the membrane, $B$ is the solute permeability coefficient of the membrane, and $\Delta C$ is the concentration gradient of solute on either side of the membrane.

The coefficient $A$ (Eq. (1)) depends on three variables: osmotic pressure on the membrane surface $\left(\pi_{m_{i}}\right), T$, and the flow factor $(F F)$ related to fouling and operating time [38].

$A=A\left(A_{0}, \pi_{\mathrm{m}_{\mathrm{i}}}\right) \cdot T C F \cdot F F$

where $A_{0}$ is the initial water permeability coefficient, and TCF is the temperature correction factor.

$\pi_{\mathrm{m}_{\mathrm{i}}}=\pi_{\mathrm{f}_{\mathrm{i}}} \cdot \frac{C_{\mathrm{fb}_{\mathrm{i}}}}{C_{\mathrm{f}_{\mathrm{i}}}} \cdot P F_{\mathrm{i}}$

where $\pi_{\mathrm{f}_{\mathrm{i}}}$ is the osmotic pressure of the feedwater, and $P F_{\mathrm{i}}$ is the concentration polarization factor of the membrane element $\mathrm{i}$.

$\pi_{\mathrm{f}_{\mathrm{i}}}=0.0787 \cdot(273+T) \cdot \Sigma m_{\mathrm{j}}$

$C_{\mathrm{m}_{\mathrm{i}}}=C_{\mathrm{fb}_{\mathrm{i}}} \cdot P F_{\mathrm{i}}$

$C_{\mathrm{fb}_{\mathrm{i}}}=C_{\mathrm{f}_{\mathrm{i}}}\left(\frac{1+\frac{C_{\mathrm{bi}}}{C_{\mathrm{fi}}}}{2}\right)$

$P F_{\mathrm{i}}=\mathrm{e}^{0.7 \cdot Y_{\mathrm{i}}}$

$Y_{\mathrm{i}}$ is the element recovery as a fraction. An additional module was developed to calculate $P F_{\mathrm{i}}$ using Eq. (9).

$P F_{\mathrm{i}}=\frac{C_{\mathrm{m}}}{C_{\mathrm{fb}}}$

- The TCF is calculated as follows [39]:

If $T \geqslant 25^{\circ} \mathrm{C}$ :

$T C F=\exp \left[2,640 \cdot\left(\frac{1}{298}-\frac{1}{273+T}\right)\right]$

If $T \leqslant 25^{\circ} \mathrm{C}$ :
$T C F=\exp \left[3,020 \cdot\left(\frac{1}{298}-\frac{1}{273+T}\right)\right]$

FF (Flow factor) is the coefficient used for considering operating time and fouling. A value of 1 was used to estimate the performance as new Filmtec ${ }^{\mathrm{TM}} \mathrm{BW} 30-400$ elements were considered. Next in the development of Eq. (1) is the expression of the $N D P$, which depends on $p_{\mathrm{f}_{\mathrm{i}}}$, $\Delta p_{\mathrm{fb}_{\mathrm{i}}}, p_{\mathrm{p}_{\mathrm{i}}}, \pi_{\mathrm{m}_{\mathrm{i}}}$ and the average osmotic pressure of the permeate $\left(\pi_{\mathrm{p}_{\mathrm{i}}}\right)$ :

$N D P=(\Delta p-\Delta \pi)=p_{\mathrm{f}_{\mathrm{i}}}-\frac{\Delta p_{\mathrm{fb}_{\mathrm{i}}}}{2}-p_{\mathrm{p}_{\mathrm{i}}}-\pi_{\mathrm{m}_{\mathrm{i}}}+\pi_{\mathrm{p}_{\mathrm{i}}}$

$\Delta p_{\mathrm{fb}_{\mathrm{i}}}$ depends on two parameters obtained experimentally ( $a$ and $b$ ) and the average feed-brine flow:

$\Delta p_{\mathrm{fb}_{\mathrm{i}}}=\left(\mathrm{a} \cdot\left(\frac{Q_{\mathrm{f}_{\mathrm{i}}}+Q_{\mathrm{r}_{\mathrm{i}}}}{2}\right)^{\mathrm{b}}\right) \cdot 0.07$

Eq. (13) is multiplied by 0.07 due to unit conversion, from psi to $\mathrm{kg}$ $\mathrm{cm}^{-2}$. In order to calculate $\pi_{\mathrm{p}_{\mathrm{i}}}$, the average ionic permeability coefficient (B) has to be multiplied by TCF (Eq. (14)), since $B$ depends on $T$. This enables calculation of the ion concentration of the permeate $\left(C_{\mathrm{p}_{\mathrm{j}}}\right)$ :

$C_{\mathrm{p}_{\mathrm{j}}}=B_{\mathrm{j}} \cdot P F_{\mathrm{i}} \cdot T C F \cdot \frac{S_{\mathrm{m}}}{Q_{\mathrm{p}_{\mathrm{i}}}} \cdot\left(\frac{C_{\mathrm{f}_{\mathrm{j}}} \cdot\left(1+F C_{\mathrm{i}}\right)}{2}\right)$

Once $C_{\mathrm{pj}}$ is obtained, $\pi_{\mathrm{p}_{\mathrm{i}}}$ is calculated according to Eq. (5). First, $Q_{\mathrm{pi}}$ is calculated, and with that, $Y_{\mathrm{i}}$, and then the result is compared to the estimation. Therefore, the function to minimize is the difference between both element recoveries. Knowing the interval of the variable $(0-1)$, the MATLAB $^{\circledast}$ optimizing function $[40,41]$ was used to find the solution.

\subsection{Simulation considerations}

The constraints considered were those established by the membrane manufacturer for the Filmtec ${ }^{\mathrm{TM}} \mathrm{BW} 30-400$ element: minimum rejection flow $\left(Q_{\mathrm{r}-\min }=3 \mathrm{~m}^{3} \mathrm{~h}^{-1}\right)$, maximum permeate flow $\left(Q_{\mathrm{p}-\max }=1.43 \mathrm{~m}^{3}\right.$ $\left.\mathrm{h}^{-1}\right)$, maximum feed flow $\left(Q_{\mathrm{a}-\max }=17 \mathrm{~m}^{3} \mathrm{~h}^{-1}\right)$ and maximum recovery per membrane element $\left(R_{\max -\mathrm{i}}=19 \%\right)$, all according to the origin and $S D I$ of the feedwater (well water and $S D I<3$ ) [38]. The feed pressure range considered was between 7 and 20 bar in steps of 0.5 bar, and the feed flow range between $Q_{r-\min }$ and $Q_{\mathrm{a}-\max }$ in steps of $10 \mathrm{~m}^{3}$ $\mathrm{d}^{-1}$. The $S E C$ was calculated considering a $100 \%$ efficiency of the high pressure pump and electrical engine. A profit simulation was also carried out assuming an energy consumption cost range of $0.09-0.16 €$ $\mathrm{kWh}^{-1}(\beta)$ and a water sale price range of $0.2-0.55 € \mathrm{~m}^{-1}(\alpha)$. These ranges were determined in accordance with established prices in the Canary archipelago. A simple profit $(P R)$ function was used for the assessment (Eq. (15)).

$P R=Q_{\mathrm{p}} \cdot(\alpha-\beta \cdot S E C)$

\section{Results and discussion}

Table 3 shows the $R_{\max }$ obtained for each antiscalant. The limiting compounds were $\mathrm{CaCO}_{3}$ and $\mathrm{SiO}_{2}$. In most cases, the highest values were obtained with the Vitec 4000 (specific silica inhibitor) antiscalant. The range of $R_{\max }$ for each antiscalant along the 24 samples is quite pronounced; from 21.25 to 76.47 , from 7.25 to 76.47 , from 31.82 to 76.47 and from 70.81 to 89.07 for the Genesys LF, Genesys SI, Vitec 3000 and Vitec 4000 antiscalants, respectively.

Figs. 1 and 2 show the ideal SEC in the operation windows for both BWRO systems considered with sample 1. A wider operation window can be seen for the 3:2 than the 2:1 configuration. This is because the $3: 2$ configuration has one more $\mathrm{PV}$ in the second stage, allowing the system to work with higher $Q_{\mathrm{f}}$ per PV in the first stage without exceeding the constraints established by the RO membrane manufacturer. 
Table 3

$R_{\max }$ for each antiscalant

\begin{tabular}{|c|c|c|c|c|}
\hline Sample & Genesys LF & Genesys SI & Vitec 3000 & Vitec 4000 \\
\hline 1 & 52.70 & 52.70 & 52.70 & 76.35 \\
\hline 2 & 72.04 & 72.04 & 72.04 & 86.02 \\
\hline 3 & 56.31 & 56.31 & 56.31 & 80.48 \\
\hline 4 & 59.37 & 59.37 & 59.37 & 82.53 \\
\hline 5 & 58.76 & 58.76 & 58.76 & 80.59 \\
\hline 6 & 49.44 & 49.44 & 49.44 & 75.53 \\
\hline 7 & 55.51 & 55.51 & 55.51 & 77.76 \\
\hline 8 & 55.29 & 55.29 & 55.29 & 77.65 \\
\hline 9 & 76.39 & 76.39 & 76.39 & 89.07 \\
\hline 10 & 54.03 & 54.03 & 54.03 & 79.16 \\
\hline 11 & 75.19 & 75.19 & 75.19 & 84.78 \\
\hline 12 & 76.47 & 76.47 & 76.47 & 84.48 \\
\hline 13 & 55.99 & 55.99 & 55.99 & 80.60 \\
\hline 14 & 56.31 & 56.31 & 56.31 & 78.15 \\
\hline 15 & 31.82 & 31.82 & 31.82 & 70.81 \\
\hline 16 & 57.11 & 57.11 & 57.11 & 81.21 \\
\hline 17 & 56.81 & 56.81 & 56.81 & 78.41 \\
\hline 18 & 70.00 & 70.00 & 70.00 & 79.30 \\
\hline 19 & 60.48 & 60.48 & 60.48 & 80.24 \\
\hline 20 & 68.05 & 68.05 & 68.05 & 82.40 \\
\hline 21 & 32.86 & 20.86 & 70.86 & 73.84 \\
\hline 22 & 21.25 & 7.25 & 42.25 & 72.53 \\
\hline 23 & 52.75 & 52.75 & 52.75 & 73.84 \\
\hline 24 & 53.24 & 53.24 & 53.24 & 78.93 \\
\hline
\end{tabular}

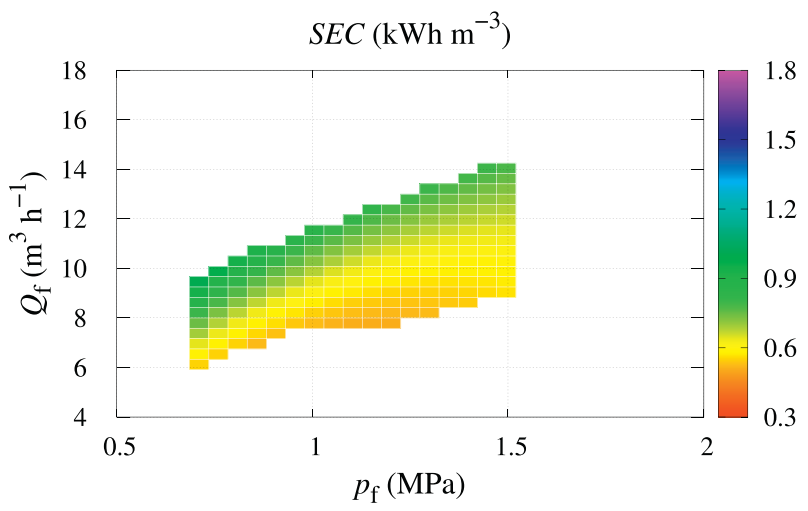

Fig. 1. SEC in the operation window for the configuration 2(6):1(6) and sample

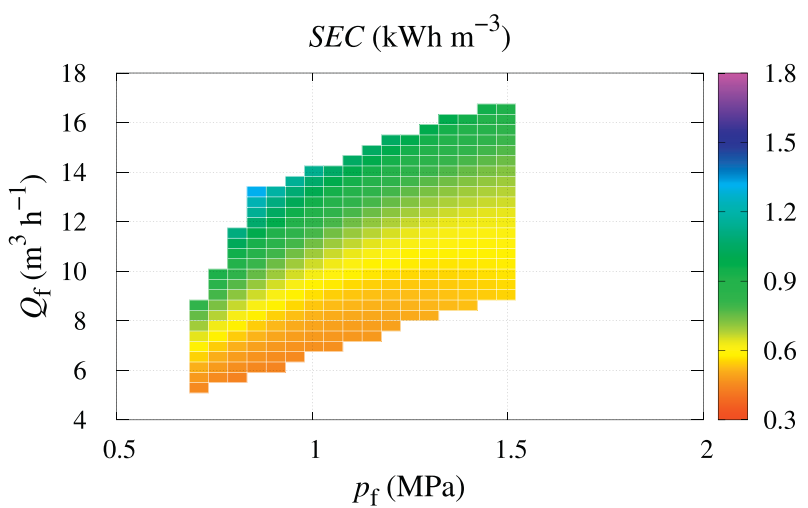

Fig. 2. SEC in the operation window for the configuration 3(6):2(6) and sample 1.

As can be seen, the color distribution is more or less similar, with the lowest $S E C$ values in both figures found in the interval between 0.7 and 1.2 MPa and, in terms of $Q_{\mathrm{f}}$ per PV in the first stage, in the interval between 5 and $8 \mathrm{~m}^{3} \mathrm{~h}^{-1}$. It is possible to obtain minimum $S E C$ values below $0.5 \mathrm{kWh} \mathrm{m}^{-3}$ with both configurations.

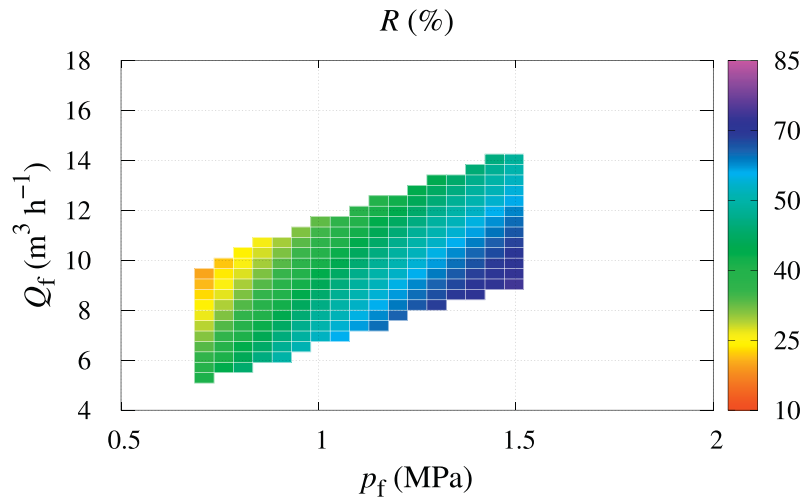

Fig. 3. $R$ in the operation window for the configuration 2(6):1(6) and sample 1 .

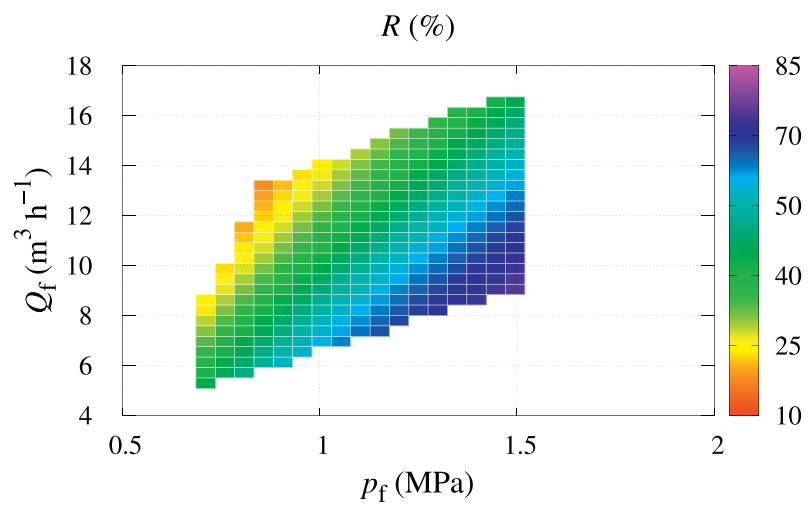

Fig. 4. $R$ in the operation window for the configuration 3(6):2(6) and sample 1

If we compare Figs. 1 and 2 with Figs. 3 and 4, which show the corresponding $R$ values, it can be seen that the areas with low $S E C$ values do not necessarily correspond to areas with high $R$ values, and that a high $R$ value does not always imply a high SEC value. The highest $R$ are found in the interval between 1 and $1.5 \mathrm{MPa}$ and, in terms of $Q_{\mathrm{f}}$ per PV in the first stage, in the interval between 7 and $12 \mathrm{~m}^{3} \mathrm{~h}^{-1}$. Relatively high $R$ can be achieved with the ideal SEC of between approximately 0.5 and $0.6 \mathrm{kWh} \mathrm{m}^{-3}$ for both configurations and this inorganic composition (sample 1). It should be mentioned that the $R$ adopted depends on the antiscalant used. Three of the antiscalant products considered would allow operation with $R$ values of up to $52 \%$. Only the Vitec 4000 would allow operation with $R$ close to $72 \%$. However, the highest $R$ is not necessarily the best option, as specific silica antiscalant usually costs around twice as much as other antiscalants [42].

Figs. 5 and 6 show the trend of $T D S_{\mathrm{p}}$ in the operation window for both BWRO systems. In general, $T D S_{\mathrm{p}}$ decreases as $p_{\mathrm{f}}$ increases. Higher $T D S_{\mathrm{p}}$ values are found at low pressure for the entire range of $Q_{\mathrm{f}}$ per PV in the first stage. This trend is in accordance with the data provided by the membrane manufacturer (Dupont ${ }^{\circledR}$ ), calculated using its WAVE software program.

Feedwater fluctuations in terms of $T$, inorganic composition and $T D S_{\mathrm{f}}$ can have a significant impact on the operation window of a BWRO system. The effect of TDS can be seen if we compare the SEC values shown in Figs. 1 and 2 for sample 1 (with a $T D S_{\mathrm{f}}$ value of $1.2 \mathrm{~g} \mathrm{~L}^{-1}$ ) with those shown in Figs. 7 and 8 for sample 20 (with a $T D S_{\mathrm{f}}$ value of $4.4 \mathrm{~g} \mathrm{~L}^{-1}$ ). It can be seen how the operation window is smaller and $S E C$ is lower for sample 20 in both configurations. The lower $T D S_{\mathrm{f}}$ of sample 20 translates into higher $Q_{\mathrm{p}}$ in the first stage in comparison with sample 1 , making it more likely that the constraints are not met in terms of $Q_{\mathrm{r}-\min }$ and $R_{\max -\mathrm{i}}$.

With the characteristics of sample 20 , some operating points are reached that would be not appropriate with other samples according to 


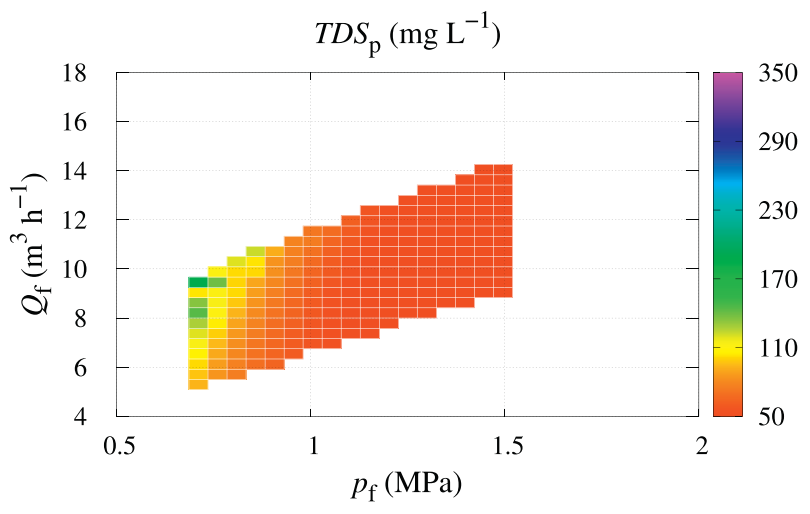

Fig. 5. $T D S_{\mathrm{p}}$ in the operation window for the configuration 2(6):1(6) and sample 1.

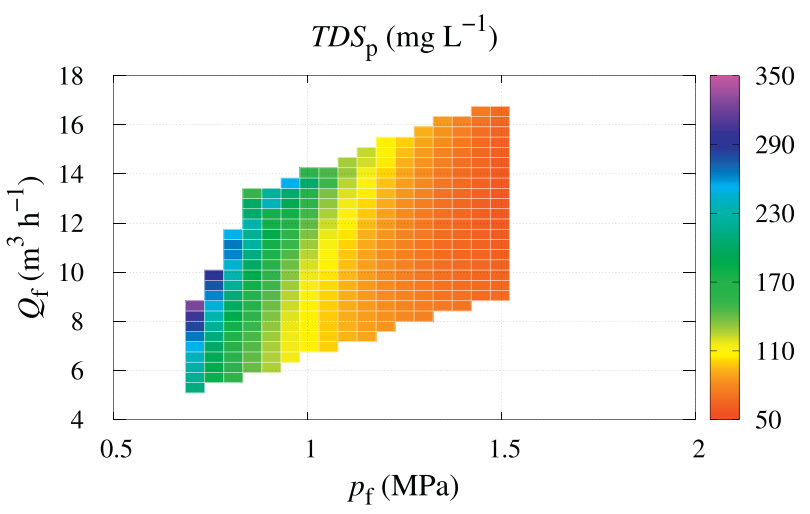

Fig. 6. $T D S_{\mathrm{p}}$ in the operation window for the configuration 3(6):2(6) and sample 1.

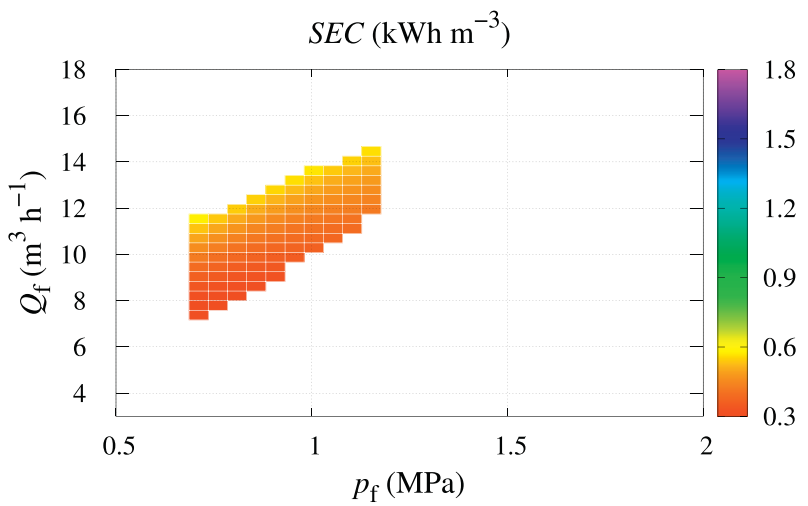

Fig. 7. SEC in the operation window for the configuration 2(6):1(6) and sample 20.

the constraints imposed by the membrane manufacturer. Figs. 9 and 10 show respectively the average SEC and $R$ in the common operation window for all 24 samples considering the 2:1 configuration. The Ebara EVMS20 16/18.5 pump was selected to show the possible operating curves when working with a variable frequency drive. The pump was oversized to take into account future effects of fouling on the BWRO systems. For the 2:1 configuration, the 24-sample average SEC, average maximum $S E C$ and average minimum $S E C$ of this common operation window were $0.760,1.198$ and $0.339 \mathrm{kWh} \mathrm{m}^{-3}$, respectively, while the corresponding $R$ values were 33.47, 67.66 and 19.86\%. Figs. 11 and 12 show respectively the average $S E C$ and $R$ in the common operation window for all 24 samples considering the 3:2 configuration. In this case, the operating window was wider and, as 3 PVs were deployed in

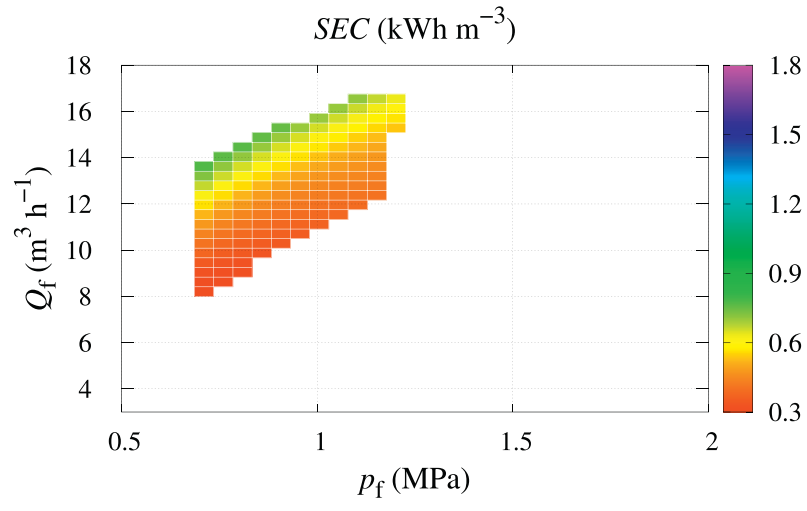

Fig. 8. $S E C$ in the operation window for the configuration 3(6):2(6) and sample 20 .

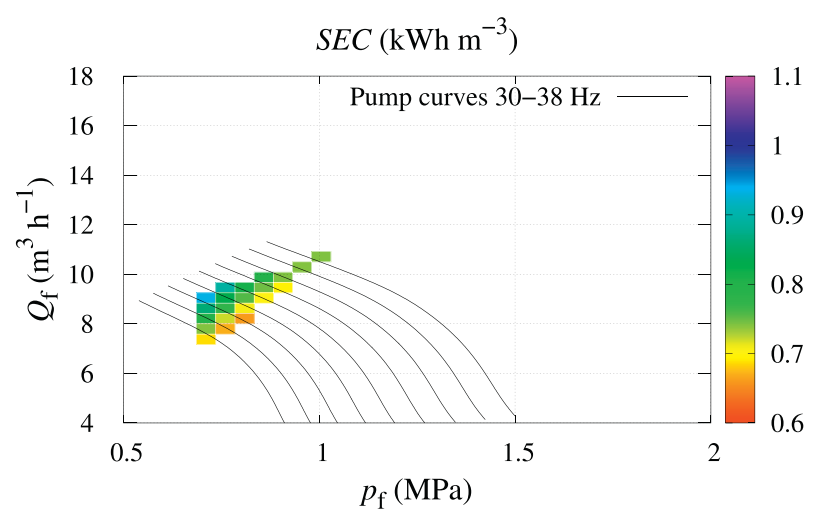

Fig. 9. Pump curves and average $S E C$ in the common operation window for the configuration 2(6):1(6) and considering the 24 samples.

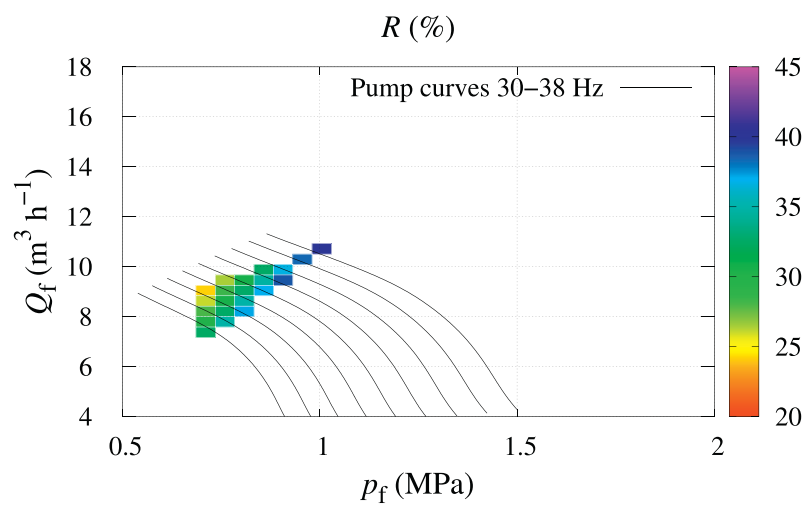

Fig. 10. Pump curves and average $R$ in the common operation window for the configuration 2(6):1(6) and considering the 24 samples.

the first stage, a larger pump (Ebara EVMS45 6-0F5/22) was required to operate with this configuration. The values obtained are noticeably different to those obtained with the 2:1 configuration. For the 3:2 configuration, the 24-sample average $S E C$, average maximum $S E C$ and average minimum $S E C$ of this common operation window were 0.933 , 1.494 and $0.410 \mathrm{kWh} \mathrm{m}^{-3}$, respectively, while the corresponding $R$ values were $30.52,61.52$ and $18.17 \%$.

Tables 4 and 5 show the operating points that correspond to the minimum $S E C$ value for each of the 24 samples with the 2:1 and 3:2 configurations, respectively. For the 2:1 configuration (Table 4), $p_{\mathrm{f}}$ ranges between 0.74 and $0.98 \mathrm{MPa}$ and shows a general tendency to increase with $T D S_{\mathrm{f}}$, while $Q_{\mathrm{f}}$ ranges between 5.08 and $7.17 \mathrm{~m}^{3} \mathrm{~h}^{-1}$ in the first stage and per PV and shows a general tendency to increase as 


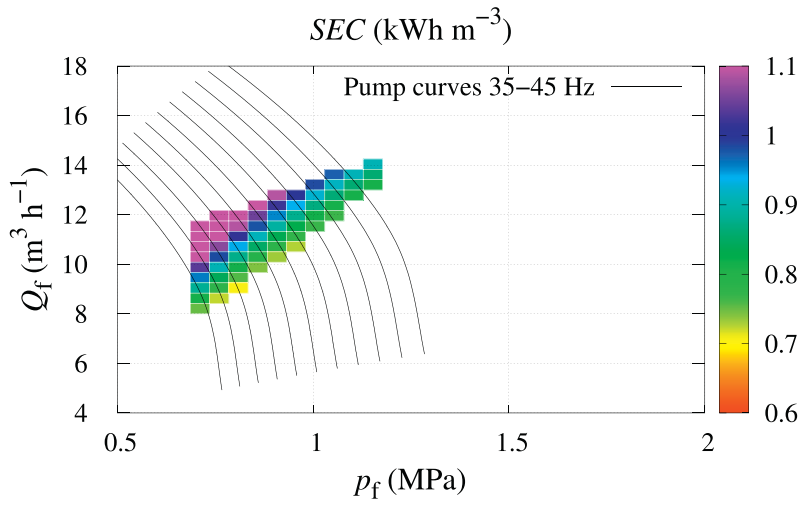

Fig. 11. Pump curves and average $S E C$ in the common operation window for the configuration 3(6):2(6) and considering the 24 samples.

\section{$R(\%)$}

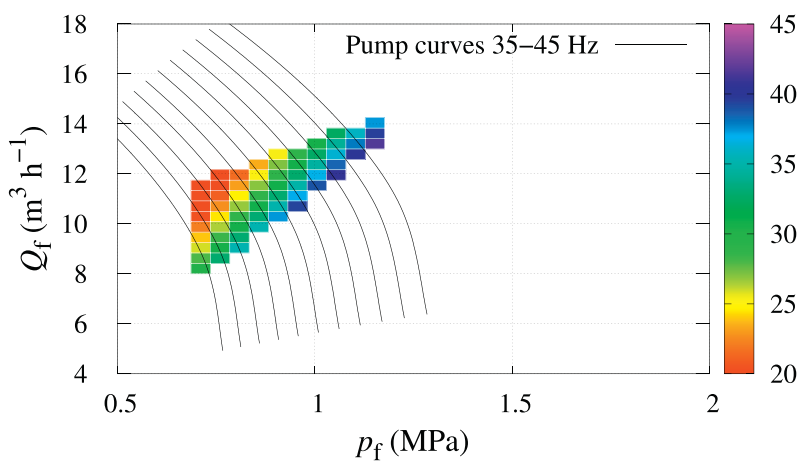

Fig. 12. Pump curves and average $R$ in the common operation window for the configuration 3(6):2(6) and considering the 24 samples.

Table 4

Operating points of minimum SEC for configuration 2(6):1(6).

\begin{tabular}{|c|c|c|c|c|c|}
\hline Sample & $\begin{array}{l}p_{\mathrm{f}} \\
(\mathrm{MPa})\end{array}$ & $\begin{array}{l}Q_{\mathrm{f}} \\
\left(\mathrm{m}^{3} \mathrm{~h}^{-1}\right)\end{array}$ & $\begin{array}{l}R \\
(\%)\end{array}$ & $\begin{array}{l}\operatorname{TDS}_{\mathrm{p}} \\
\left(\mathrm{mg} \mathrm{L}^{-1}\right)\end{array}$ & $\begin{array}{l}\text { SEC } \\
\left(\mathrm{kWh} \mathrm{m}^{-3}\right)\end{array}$ \\
\hline 1 & 0.83 & 5.50 & 51.95 & 71.01 & 0.446 \\
\hline 2 & 0.74 & 5.50 & 44.68 & 84.86 & 0.432 \\
\hline 3 & 0.83 & 5.50 & 51.04 & 72.99 & 0.454 \\
\hline 4 & 0.78 & 5.50 & 51.74 & 68.51 & 0.421 \\
\hline 5 & 0.74 & 5.92 & 57.63 & 51.95 & 0.355 \\
\hline 6 & 0.78 & 5.50 & 52.46 & 69.21 & 0.415 \\
\hline 7 & 0.93 & 5.50 & 50.31 & 77.71 & 0.514 \\
\hline 8 & 0.74 & 5.08 & 47.99 & 80.77 & 0.426 \\
\hline 9 & 0.83 & 5.50 & 52.19 & 69.22 & 0.444 \\
\hline 10 & 0.88 & 5.50 & 51.54 & 77.58 & 0.476 \\
\hline 11 & 0.98 & 5.50 & 49.28 & 49.28 & 0.553 \\
\hline 12 & 0.98 & 5.50 & 49.05 & 86.98 & 0.555 \\
\hline 13 & 0.78 & 5.50 & 51.12 & 70.25 & 0.426 \\
\hline 14 & 0.88 & 5.50 & 52.01 & 72.15 & 0.471 \\
\hline 15 & 0.83 & 5.50 & 52.17 & 70.30 & 0.444 \\
\hline 16 & 0.88 & 5.50 & 49.64 & 77.22 & 0.494 \\
\hline 17 & 0.93 & 5.50 & 52.68 & 71.34 & 0.491 \\
\hline 18 & 0.88 & 5.50 & 50.95 & 75.46 & 0.481 \\
\hline 19 & 0.83 & 5.50 & 51.36 & 71.82 & 0.451 \\
\hline 20 & 0.74 & 7.17 & 75.69 & 22.97 & 0.270 \\
\hline 21 & 0.74 & 5.92 & 54.89 & 57.82 & 0.372 \\
\hline 22 & 0.74 & 5.92 & 57.79 & 52.61 & 0.354 \\
\hline 23 & 0.74 & 7.17 & 70.28 & 27.52 & 0.291 \\
\hline 24 & 0.78 & 5.50 & 53.34 & 75.75 & 0.409 \\
\hline
\end{tabular}

$T D S_{\mathrm{f}}$ decreases. $R$ (ranging between 44.68 and $75.69 \%$ ) shows the same general tendency with respect to $T D S_{\mathrm{f}}$ as $Q_{\mathrm{f}}$. $T D S_{\mathrm{p}}$ ranges between 22.97 and $86.98 \mathrm{mg} \mathrm{L}^{-1}$, and minimum $S E C$ between 0.27 and $0.56 \mathrm{kWh}$ $\mathrm{m}^{-3}$. SEC shows a tendency to decrease with $T D S_{\mathrm{f}}$. The results obtained
Table 5

Operating points of minimum SEC for configuration 3(6):2(6).

\begin{tabular}{rlllll}
\hline Sample & $\begin{array}{l}p_{\mathrm{f}} \\
(\mathrm{MPa})\end{array}$ & $\begin{array}{l}Q_{\mathrm{f}} \\
\left(\mathrm{m}^{3} \mathrm{~h}^{-1}\right)\end{array}$ & $\begin{array}{l}R \\
(\%)\end{array}$ & $\begin{array}{l}T D S_{\mathrm{p}} \\
\left(\mathrm{mg} \mathrm{L}^{-1}\right)\end{array}$ & $\begin{array}{l}\text { SEC } \\
\left(\mathrm{kWh} \mathrm{m}^{-3}\right)\end{array}$ \\
\hline 1 & 0.83 & 5.50 & 54.40 & 145.62 & 0.426 \\
2 & 0.74 & 5.50 & 47.41 & 187.04 & 0.410 \\
3 & 0.83 & 5.50 & 53.51 & 149.48 & 0.433 \\
4 & 0.78 & 5.50 & 54.37 & 145.79 & 0.401 \\
5 & 0.74 & 5.92 & 60.78 & 116.24 & 0.336 \\
6 & 0.78 & 5.50 & 55.06 & 147.48 & 0.396 \\
7 & 0.93 & 5.50 & 52.49 & 149.93 & 0.493 \\
8 & 0.74 & 5.08 & 50.56 & 179.39 & 0.404 \\
9 & 0.83 & 5.50 & 54.67 & 141.97 & 0.424 \\
10 & 0.88 & 5.50 & 53.85 & 154.07 & 0.455 \\
11 & 0.98 & 5.50 & 51.36 & 51.36 & 0.530 \\
12 & 0.98 & 5.50 & 51.17 & 163.54 & 0.532 \\
13 & 0.78 & 5.50 & 53.75 & 149.33 & 0.405 \\
14 & 0.88 & 5.50 & 54.31 & 143.31 & 0.451 \\
15 & 0.83 & 5.50 & 54.63 & 144.19 & 0.424 \\
16 & 0.88 & 5.50 & 51.98 & 152.92 & 0.472 \\
17 & 0.83 & 5.08 & 49.21 & 170.08 & 0.471 \\
18 & 0.88 & 5.50 & 53.23 & 149.82 & 0.461 \\
19 & 0.83 & 5.50 & 53.79 & 147.22 & 0.430 \\
20 & 0.69 & 7.58 & 71.22 & 56.10 & 0.268 \\
21 & 0.69 & 5.50 & 55.58 & 148.18 & 0.343 \\
22 & 0.74 & 5.92 & 60.91 & 117.79 & 0.335 \\
23 & 0.69 & 7.17 & 69.32 & 69.33 & 0.275 \\
24 & 0.78 & 5.50 & 55.98 & 161.47 & 0.389 \\
\hline & & & & & \\
\hline
\end{tabular}

Table 6

Operating points of $R_{\max }$ for configuration 2(6):1(6).

\begin{tabular}{rlrlll}
\hline Sample & $\begin{array}{l}p_{\mathrm{f}} \\
(\mathrm{MPa})\end{array}$ & $\begin{array}{l}Q_{\mathrm{f}} \\
\left(\mathrm{m}^{3} \mathrm{~h}^{-1}\right)\end{array}$ & $\begin{array}{l}S E C \\
\left.(\mathrm{kWh} \mathrm{m})^{-3}\right)\end{array}$ & $\begin{array}{l}T D S_{\mathrm{p}} \\
\left(\mathrm{mg} \mathrm{L}^{-1}\right)\end{array}$ & $\begin{array}{l}R \\
(\%)\end{array}$ \\
\hline 1 & 1.52 & 8.83 & 0.564 & 40.99 & 74.82 \\
2 & 1.47 & 8.83 & 0.547 & 41.70 & 74.72 \\
3 & 1.52 & 8.83 & 0.569 & 41.52 & 74.22 \\
4 & 1.47 & 9.25 & 0.545 & 37.83 & 74.94 \\
5 & 1.37 & 9.67 & 0.482 & 30.84 & 79.06 \\
6 & 1.47 & 9.25 & 0.542 & 38.73 & 75.44 \\
7 & 1.62 & 8.83 & 0.629 & 45.17 & 71.41 \\
8 & 1.47 & 8.83 & 0.545 & 40.99 & 75.04 \\
9 & 1.52 & 8.83 & 0.563 & 40.01 & 74.95 \\
10 & 1.57 & 8.83 & 0.594 & 45.22 & 73.33 \\
11 & 1.67 & 8.42 & 0.656 & 52.79 & 70.61 \\
12 & 1.72 & 8.42 & 0.665 & 50.72 & 71.74 \\
13 & 1.47 & 9.25 & 0.548 & 38.44 & 74.55 \\
14 & 1.57 & 8.83 & 0.592 & 42.25 & 73.64 \\
15 & 1.32 & 8.00 & 0.521 & 44.36 & 70.53 \\
16 & 1.62 & 8.83 & 0.612 & 43.27 & 73.47 \\
17 & 1.62 & 8.83 & 0.616 & 42.64 & 72.94 \\
18 & 1.57 & 8.83 & 0.597 & 43.70 & 73.00 \\
19 & 1.52 & 8.83 & 0.567 & 41.18 & 74.48 \\
20 & 1.13 & 10.92 & 0.383 & 15.74 & 81.72 \\
21 & 1.18 & 8.42 & 0.445 & 36.91 & 73.42 \\
22 & 1.32 & 10.92 & 0.508 & 29.03 & 72.35 \\
23 & 1.23 & 12.58 & 0.462 & 16.36 & 73.70 \\
24 & 1.47 & 9.25 & 0.538 & 42.79 & 75.94 \\
\hline
\end{tabular}

are quite similar to those for the $3: 2$ configuration in terms of $p_{\mathrm{f}}$ (0.69-0.98 MPa), $Q_{\mathrm{f}}\left(5.08-7.58 \mathrm{~m}^{3} \mathrm{~h}^{-1}\right), R(47.41-71.22 \%), T D S_{\mathrm{p}}$ (51.36-187.04 $\mathrm{mg} \mathrm{L}^{-1}$ ) and SEC $\left(0.27-0.53 \mathrm{kWh} \mathrm{m}^{-3}\right)$. The $R$ in the first stage was in a similar interval for both configurations of between 42.64 and $50.19 \%$ (data not shown).

Tables 6 and 7 show the operating points that correspond to the maximum $R_{\max }$ for the two BWRO configurations considered. In this case, the ranges of $p_{\mathrm{f}}$ for both configurations are higher, 1.13-1.72 and 0.88-1.72 MPa for the 2:1 and 3:2 configuration, respectively. The $Q_{\mathrm{f}}$ ranges are also found to be higher for the operating points of $R_{\max }$ than for those of minimum SEC. The TDS $\mathrm{p}_{\mathrm{p}}$ are lower and the ranges of SEC higher, from 0.38 to 0.67 and $0.33-0.65 \mathrm{kWh} \mathrm{m}^{-3}$ for the $2: 1$ and $3: 2$ configurations, respectively. The highest $R_{\max }$ value was obtained for 
Table 7

Operating points of $R_{\max }$ for configuration 3(6):2(6).

\begin{tabular}{rlrlll}
\hline Sample & $\begin{array}{l}p_{\mathrm{f}} \\
(\mathrm{MPa})\end{array}$ & $\begin{array}{c}Q_{\mathrm{f}} \\
\left(\mathrm{m}^{3} \mathrm{~h}^{-1}\right)\end{array}$ & $\begin{array}{l}\text { SEC } \\
\left.(\mathrm{kWh} \mathrm{m})^{-3}\right)\end{array}$ & $\begin{array}{l}T D S_{\mathrm{p}} \\
\left.(\mathrm{mg} \mathrm{L})^{-1}\right)\end{array}$ & $R(\%)$ \\
\hline 1 & 1.52 & 8.83 & 0.553 & 68.42 & 76.33 \\
2 & 1.47 & 8.83 & 0.536 & 70.20 & 76.29 \\
3 & 1.52 & 8.83 & 0.557 & 69.25 & 75.78 \\
4 & 1.47 & 9.25 & 0.533 & 63.74 & 76.69 \\
5 & 1.37 & 10.08 & 0.477 & 51.69 & 79.97 \\
6 & 1.47 & 10.08 & 0.543 & 62.01 & 75.21 \\
7 & 1.62 & 8.83 & 0.616 & 73.87 & 72.96 \\
8 & 1.47 & 8.83 & 0.533 & 69.05 & 76.64 \\
9 & 1.52 & 8.83 & 0.552 & 66.82 & 76.48 \\
10 & 1.57 & 8.83 & 0.582 & 74.69 & 74.85 \\
11 & 1.67 & 8.42 & 0.643 & 85.63 & 72.03 \\
12 & 1.72 & 8.42 & 0.652 & 81.86 & 73.10 \\
13 & 1.47 & 9.25 & 0.535 & 64.73 & 76.32 \\
14 & 1.57 & 8.83 & 0.580 & 69.84 & 75.15 \\
15 & 1.47 & 10.50 & 0.577 & 63.31 & 70.76 \\
16 & 1.62 & 8.83 & 0.600 & 70.97 & 74.94 \\
17 & 1.62 & 8.83 & 0.604 & 69.89 & 74.45 \\
18 & 1.57 & 8.83 & 0.585 & 72.16 & 74.50 \\
19 & 1.52 & 8.83 & 0.556 & 68.71 & 75.97 \\
20 & 1.18 & 12.17 & 0.397 & 25.92 & 82.39 \\
21 & 1.23 & 9.67 & 0.462 & 60.02 & 73.64 \\
22 & 1.23 & 10.50 & 0.470 & 53.80 & 72.41 \\
23 & 0.88 & 9.25 & 0.333 & 45.21 & 73.56 \\
24 & 1.47 & 9.25 & 0.526 & 72.21 & 77.64 \\
\hline & & & & & \\
\hline
\end{tabular}

sample 20 and the lowest for sample 15, reflecting the different inorganic compositions of the samples (Tables 1 and 3).

The profit analysis that was made of the common operating windows showed that the most profitable operating points were those with the highest $R, p_{\mathrm{f}}=1.03 \mathrm{MPa}$ and $Q_{\mathrm{f}}=10.5 \mathrm{~m}^{3} \mathrm{~h}^{-1}$ for the $2: 1$ configuration, and $p_{\mathrm{f}}=1.18 \mathrm{MPa}$ and $Q_{\mathrm{f}}=13 \mathrm{~m}^{3} \mathrm{~h}^{-1}$ for the $3: 2$ configuration. The weight of $\alpha$ was higher than $\beta$ as the Canary Archipelago is a region with subsidized electrical energy costs and desalinated water has a high value due to water scarcity in the region. The calculated profit values ranged between 0.79 and $4.4 € \mathrm{~h}^{-1}$ and between 1.33 and $8.36 € \mathrm{~h}^{-1}$ for the $2: 1$ and 3:2 configurations, respectively. It should be noted that the corresponding profit values are affected by the fact that $Q_{\mathrm{p}}$ is higher for the 3:2 than the 2:1 configuration due to its higher $Q_{\mathrm{f}}$. It should be mentioned that the capital costs would be higher for the configuration 3:2 as more PVs and membrane elements would be installed.

\section{Conclusions}

In this study, the operation windows of two BWRO system configurations (2(6):1(6) and 3(6):2(6)) were evaluated using the fluctuations of the characteristics of the feedwater from a real groundwater well. The optimal operating points for each sample were determined in terms of minimum SEC and maximum $R$. The operating margins were found to be quite wide. The operating parameters of the BWRO systems were significantly influenced by fluctuations in the feedwater characteristics. In general, the operating windows were wider for the 3:2 than the 2:1 configuration. With such variability, it would be appropriate to design flexible BWRO systems which are capable of working at least in the common operation window. In these cases, it could be interesting to implement real-time control strategies in order to maximally optimize the operation through observation of fluctuations in the inorganic composition of the feedwater. From the economic point of view, the operating points of the common operation windows with the highest $R$ were found to be the most profitable according to the prices established in the region were the groundwater is located. In future works, changes in the operation windows and optimal operating points as the membranes get fouled should be evaluated.

\section{CRediT authorship contribution statement}

A. Ruiz-García:Conceptualization, Methodology, Writing - original draft, Visualization, Investigation, Validation, Writing - review \& editing.I. Nuez:Conceptualization, Resources, Supervision.M.D. Carrascosa-Chisvert:Data curation, Investigation, Formal analysis.J.J. Santana:Data curation, Investigation, Supervision, Formal analysis.

\section{Declaration of competing interest}

The authors declare that they have no known competing financial interests or personal relationships that could have appeared to influence the work reported in this paper.

\section{References}

[1] M. Qasim, M. Badrelzaman, N.N. Darwish, N.A. Darwish, N. Hilal, Reverse osmosis desalination: a state-of-the-art review, Desalination 459 (2019) 59-104, https:// doi.org/10.1016/j.desal.2019.02.008 URL http://www.sciencedirect.com/science/ article/pii/S0011916418325037.

[2] S. Burn, M. Hoang, D. Zarzo, F. Olewniak, E. Campos, B. Bolto, O. Barron, Desalination techniques-a review of the opportunities for desalination in agriculture, Desalination 364 (2015) 2-16, https://doi.org/10.1016/j.desal.2015.01. 041 desalination for Agriculture, URL http://www.sciencedirect.com/science/ article/pii/S0011916415000600.

[3] S.F. Anis, R. Hashaikeh, N. Hilal, Reverse osmosis pretreatment technologies and future trends: a comprehensive review, Desalination 452 (2019) 159-195, https:// doi.org/10.1016/j.desal.2018.11.006 URL http://www.sciencedirect.com/science/ article/pii/S0011916418320411.

[4] J. Kavitha, M. Rajalakshmi, A.R. Phani, M. Padaki, Pretreatment processes for seawater reverse osmosis desalination systems-a review, J. Water Process Eng. 32 (2019) 100926, https://doi.org/10.1016/j.jwpe.2019.100926 URL http://www. sciencedirect.com/science/article/pii/S2214714419303277.

[5] D.M. Davenport, A. Deshmukh, J.R. Werber, M. Elimelech, High-pressure reverse osmosis for energy-efficient hypersaline brine desalination: current status, design considerations, and research needs, Environ. Sci. Technol. Lett. 5 (8) (2018) 467-475, https://doi.org/10.1021/acs.estlett.8b00274 (URL doi:10.1021/acs. estlett.8b00274).

[6] D.L. Zhao, S. Japip, Y. Zhang, M. Weber, C. Maletzko, T.-S. Chung, Emerging thin film nanocomposite (TFN) membranes for reverse osmosis: a review, Water Res. 173 (2020) 115557, , https://doi.org/10.1016/j.watres.2020.115557 URL http:// www.sciencedirect.com/science/article/pii/S0043135420300932.

[7] H. Saleem, S.J. Zaidi, Nanoparticles in reverse osmosis membranes for desalination: a state of the art review, Desalination 475 (2020) 114171, , https://doi.org/10. 1016/j.desal.2019.114171 URL http://www.sciencedirect.com/science/article/ $\mathrm{pii} / \mathrm{S} 0011916419312974$

[8] S.A. Urrea, F.D. Reyes, B.P. Suárez, J.A. de la Fuente Bencomo, Technical review, evaluation and efficiency of energy recovery devices installed in the Canary Islands desalination plants, Desalination 450 (2019) 54-63, https://doi.org/10.1016/j. desal.2018.07.013 URL http://www.sciencedirect.com/science/article/pii/ S0011916417314510.

[9] A. Drak, M. Adato, Energy recovery consideration in brackish water desalination, Desalination 339 (2014) 34-39, https://doi.org/10.1016/j.desal.2014.02.008 URL http://www.sciencedirect.com/science/article/pii/S001191641400071X.

[10] Y. Okamoto, J.H. Lienhard, How RO membrane permeability and other performance factors affect process cost and energy use: a review, Desalination 470 (2019) 114064, , https://doi.org/10.1016/j.desal.2019.07.004 URL http://www. sciencedirect.com/science/article/pii/S0011916419305752.

[11] A. Ruiz-García, I. de la Nuez Pestana, Feed spacer geometries and permeability coefficients. Effect on the performance in BWRO Spriral-wound membrane modules, Water 11 (1) (2019) 1-13, https://doi.org/10.3390/w11010152 URL https:// www.mdpi.com/2073-4441/11/1/152.

[12] P.M. Biesheuvel, L. Zhang, P. Gasquet, B. Blankert, M. Elimelech, W.G.J. van der Meer, Ion selectivity in brackish water desalination by reverse osmosis: theory, measurements, and implications, Environ. Sci. Technol. Lett. 7 (1) (2020) 42-47, https://doi.org/10.1021/acs.estlett.9b00686 (URL doi:10.1021/acs.estlett. 9b00686).

[13] A. Karabelas, S.T. Mitrouli, M. Kostoglou, Scaling in reverse osmosis desalination plants: a perspective focusing on development of comprehensive simulation tools, Desalination 474 (2020) 114193, , https://doi.org/10.1016/j.desal.2019.114193 URL http://www.sciencedirect.com/science/article/pii/S0011916419313165.

[14] A. Matin, F. Rahman, H.Z. Shafi, S.M. Zubair, Scaling of reverse osmosis membranes used in water desalination: phenomena, impact, and control; future directions, Desalination 455 (2019) 135-157, https://doi.org/10.1016/j.desal.2018.12.009 URL http://www.sciencedirect.com/science/article/pii/S0011916418318897.

[15] X. Li, D. Hasson, R. Semiat, H. Shemer, Intermediate concentrate demineralization techniques for enhanced brackish water reverse osmosis water recovery - a review, Desalination 466 (2019) 24-35, https://doi.org/10.1016/j.desal.2019.05.004 URL http://www.sciencedirect.com/science/article/pii/S0011916418310816. 
[16] A. Ruiz-García, J. Feo-García, Estimation of maximum water recovery in ro desalination for different feedwater inorganic compositions, Desalin. Water Treat. 70 (2017) 34-45, https://doi.org/10.5004/dwt.2017.20476 URL http://www. deswater.com/DWT_abstracts/vol_70/70_2017_34.pdf.

[17] A. Ruiz-García, M.D. Carrascosa-Chisvert, V. Mena, R.M. Souto, J.J. Santana, I. Nuez, Groundwater quality assessment in a volcanic mountain range (South of Gran Canaria Island, Spain), Water 11 (4) (2019) 1-20, https://doi.org/10.3390/ w11040754 URL https://www.mdpi.com/2073-4441/11/4/754.

[18] A. Zhu, P.D. Christofides, Y. Cohen, Energy consumption optimization of reverse osmosis membrane water desalination subject to feed salinity fluctuation, Ind. Eng. Chem. Res. 48 (21) (2009) 9581-9589, https://doi.org/10.1021/ie900729x (URL doi:10.1021/ie900729x)

[19] M. Li, Minimization of energy in reverse osmosis water desalination using constrained nonlinear optimization, Ind. Eng. Chem. Res. 49 (4) (2010) 1822-1831, https://doi.org/10.1021/ie9012826 (URL doi:10.1021/ie9012826).

[20] M. Li, Reducing specific energy consumption in reverse osmosis (RO) water desalination: an analysis from first principles, Desalination 276 (1) (2011) 128-135, https://doi.org/10.1016/j.desal.2011.03.031 URL http://www.sciencedirect.com/ science/article/pii/S0011916411002499.

[21] Y.-Y. Lu, Y.-D. Hu, X.-L. Zhang, L.-Y. Wu, Q.-Z. Liu, Optimum design of reverse osmosis system under different feed concentration and product specification, J. Membr. Sci. 287 (2) (2007) 219-229, https://doi.org/10.1016/j.memsci.2006.10. 037 URL http://www.sciencedirect.com/science/article/pii/S0376738806007071.

[22] K.M. Sassi, I.M. Mujtaba, Optimal design and operation of reverse osmosis desalination process with membrane fouling, Chem. Eng. J. 171 (2) (2011) 582-593, https://doi.org/10.1016/j.cej.2011.04.034 URL http://www.sciencedirect.com/ science/article/pii/S1385894711004864.

[23] A. Abbas, Simulation and analysis of an industrial water desalination plant, Chem. Eng. Process. 44 (9) (2005) 999-1004, https://doi.org/10.1016/j.cep.2004.12.001 URL http://www.sciencedirect.com/science/article/pii/S0255270105000097.

[24] A. Abbas, N. Al-Bastaki, Performance decline in brackish water film tec spiral wound RO membranes, Desalination 136 (1) (2001) 281-286, https://doi.org/10 1016/S0011-9164(01)00191-6 URL http://www.sciencedirect.com/science/ article/pii/S0011916401001916.

[25] M. Li, B. Noh, Validation of model-based optimization of brackish water reverse osmosis (BWRO) plant operation, Desalination 304 (2012) 20-24, https://doi.org/ 10.1016/j.desal.2012.07.029 URL http://www.sciencedirect.com/science/article/ ii/S0011916412004006.

[26] M. Li, Optimal plant operation of brackish water reverse osmosis (BWRO) desalination, Desalination 293 (2012) 61-68, https://doi.org/10.1016/j.desal.2012.02 024 URL http://www.sciencedirect.com/science/article/pii/S0011916412001257.

[27] M. Li, Optimization of multitrain brackish water reverse osmosis (BWRO) desalination, Ind. Eng. Chem. Res. 51 (9) (2012) 3732-3739, https://doi.org/10.1021/ ie202796u (URL doi:10.1021/ie202796u).

[28] Y. Du, L. Xie, Y. Wang, Y. Xu, S. Wang, Optimization of reverse osmosis networks with spiral-wound modules, Ind. Eng. Chem. Res. 51 (36) (2012) 11764-11777, https://doi.org/10.1021/ie300650b (URL doi:10.1021/ie300650b).

[29] M. Li, A unified model-based analysis and optimization of specific energy consumption in BWRO and SWRO, Ind. Eng. Chem. Res. 52 (48) (2013) 17241-17248, https://doi.org/10.1021/ie4031083 (URL doi:10.1021/ie4031083).
[30] M.A. Al-Obaidi, A.A. Alsarayreh, A.M. Al-Hroub, S. Alsadaie, I.M. Mujtaba, Performance analysis of a medium-sized industrial reverse osmosis brackish water desalination plant, Desalination 443 (2018) 272-284, https://doi.org/10.1016/j. desal.2018.06.010 URL http://www.sciencedirect.com/science/article/pii/ S0011916418310415.

[31] A.A. Alsarayreh, M.A. Al-Obaidi, A.M. Al-Hroub, R. Patel, I.M. Mujtaba, Performance evaluation of reverse osmosis brackish water desalination plant with different recycled ratios of retentate, Comput. Chem. Eng. 135 (2020) 106729, , https://doi.org/10.1016/j.compchemeng.2020.106729 URL http://www. sciencedirect.com/science/article/pii/S0098135419310348.

[32] A.A. Alsarayreh, M.A. Al-Obaidi, A.M. Al-Hroub, R. Patel, I.M. Mujtaba, Evaluation and minimisation of energy consumption in a medium-scale reverse osmosis brackish water desalination plant, J. Clean. Prod. 248 (2020) 119220, , https://doi org/10.1016/j.jclepro.2019.119220 URL http://www.sciencedirect.com/science/ article/pii/S0959652619340909.

[33] Y.D. Ahdab, G.P. Thiel, J. Böhlke, J. Stanton, J.H. Lienhard, Minimum energy requirements for desalination of brackish groundwater in the United States with comparison to international datasets, Water Res. 141 (2018) 387-404, https://doi org/10.1016/j.watres.2018.04.015 URL http://www.sciencedirect.com/science/ article/pii/S0043135418302999.

[34] A. Ruiz-García, I. de la Nuez-Pestana, A computational tool for designing BWRO systems with spiral wound modules, Desalination 426 (2018) 69-77, https://doi org/10.1016/j.desal.2017.10.040 URL http://www.sciencedirect.com/science/ article/pii/S0011916417310950.

[35] A. Ruiz-García, E. Ruiz-Saavedra, S.O.P. Báez, Evaluation of the first seven years operating data of a RO brackish water desalination plant in Las Palmas, Canary Islands, Spain, Desalin. Water Treat. 54 (12) (2015) 3193-3199, https://doi.org/ 10.1080/19443994.2014.908145 (URL doi:10.1080/19443994.2014.908145).

[36] C.I. de Aguas de Gran Canaria, Hydrological plan of Gran Canaria, Canary government, Gran Canaria (Spain), URL, 2014. http://www.aguasgrancanaria.com/ pdfs/PlanHidro/PHart47_MemInfo.pdf.

[37] M.A. Al-Obaidi, C. Kara-Zaitri, I.M. Mujtaba, Scope and limitations of the irreversible thermodynamics and the solution diffusion models for the separation of binary and multi-component systems in reverse osmosis process, Comput. Chem. Eng. 100 (2017) 48-79, https://doi.org/10.1016/j.compchemeng.2017.02.001 URL http:// www.sciencedirect.com/science/article/pii/S0098135417300571.

[38] D.W. Solutions, Filmtec Reverse Osmosis Membranes Technical Manual, Dupont Water Solutions, 2020 URL https://www.dupont.com/content/dam/dupont/amer/ us/en/water-solutions/public/documents/en/45-D01504-en.pdf.

[39] A.R. Marsh, P.K. Eriksson, Projecting RO desalination system performance with filmtec spiral-wound elements, Proc. of the Seminar on Membrane Processes, 1988.

[40] R.P. Brent, Algorithms for Minimization Without Derivatives, Courier Corporation, 2013.

[41] G.E. Forsythe, M.A. Malcolm, C.B. Moler, Computer Methods for Mathematical Computations, Prentice-Hall, 1977.

[42] A. Ruiz-García, J. Feo-García, Antiscalant cost and maximum water recovery in reverse osmosis for different inorganic composition of groundwater, Desalin. Wate Treat. 73 (2017) 46-53, https://doi.org/10.5004/dwt.2017.20806 URL https:// www.deswater.com/DWT_abstracts/vol_73/73_2017_46.pdf. 